\title{
El papel en la salud pública de Histoplasma capsulatum
}

\author{
The public health role of Histoplasma capsulatum \\ Barrera Henao Adriana Yisell ${ }^{1}$ y González Paya Gustavo² \\ ${ }^{1} \mathrm{MVZ}$, Unillanos y ${ }^{2} \mathrm{MV}$, Esp. Docente Unillanos \\ ggonzalez@unillanos.eu.co
}

Recibido 12 de Diciembre 2014, Aceptado 26 de Septiembre 2015

\section{RESUMEN}

La histoplasmosis o citomicosis reticuloendotelial o enfermedad de las cavernas o de Darling, es causada por el hongo Histoplasma capsulatum, que por falta de políticas de control, se ha presentado altas tasas de morbi-mortalidad en humanos y animales, afectando la productividad laboral y zootécnica. Además se ha comprobado una crisis mundial, por desconocimiento del método clínico, menospreciando la importancia de la relación médico-paciente, e interrogatorio nulo. Las actividades laborales que predisponen a la presentación de la enfermedad son: espeleólogos, colectores de guano, mineros, trabajadores rurales (biólogos y veterinarios), que están en contacto directo con las aves o manipulan pollinaza y turistas que tienen contacto principalmente con cuevas, actualmente se incluyen personas que trabajan en remoción de tierra, limpieza o demolición de viejas construcciones y tala de árboles. El $H$. capsulatum posee tres grandes variedades las cuales tienen una amplia distribución geográfica y con alto potencial patogénico que afecta a humanos y animales, encontrándose que $H$. capsulatum var. capsulatum es endémico en América y algunos países de África, Asia y Europa, mientras que el $H$. capsulatum var. farciminosum (HCF), produce en equinos, la enfermedad conocida como linfangitis epizoótica, que esta reportada en África, Asia y Europa, afectando también mulares, asnales, camélidos y vacunos, que se contaminan por contacto directo con fómites y suelo, albergando esporas de este hongo, su transmisión puede darse, a través de abrasiones en el tegumento; por ejemplo por infestaciones con garrapatas como vectores mecánicos. Por otro lado en humanos, la mayoría de pacientes afectados 
tienen un curso asintomático debido a su respuesta inmunológica. El $H$. capsulatum aprovecha las células epiteliales pulmonares esperando que el hospedero se vea inmunocomprometido por otras enfermedades tales como $\mathrm{VIH}$, cáncer, alcoholismo crónico y fármacos inmunosupresores, para generar una reactivación endógena de la infección. No existen estudios que reporten contagios con este hongo, por medio del agua o alimento, ni tampoco transmisiones de persona-persona, o animal-persona. Por el momento, erradicar el hongo de los ecosistemas afectados, es realmente difícil, lo único que queda es prevención y educación a la población, para evitar la contaminación con histoplasmosis, se recomienda en personas con una inmunodepresión, no asistir a lugares que sean catalogados como reservorios del hongo como cuevas.

Palabras clave: Histoplasmosis, quirópteros, paloma, enfermedad ocupacional.

\section{ABSTRACT}

Histoplasmosis or reticuloendothelial citomicosis or cave or Darling disease, is caused by the fungus Histoplasma capsulatum, which by lack of control policies, has presented high rates of morbidity and mortality in humans and animals, affecting labor productivity and animal husbandry. It has also proved a global crisis, by ignorance of the clinical method, underestimating the importance of the doctorpatient relationship, and no interrogation. The work activities that predispose to disease presentation are: speleologists, guano collectors, mining, rural workers (biologists and veterinarians), which are in direct contact with poultry or poultry manure handling and tourists who have contact mainly with caves, currently are included people working in earthmoving, cleaning or demolition of old buildings and logging. The $H$. capsulatum has three major varieties which have a wide geographical distribution and with high pathogenic potential which affects humans and animals, found to $H$. capsulatum var. capsulatum is endemic in America and some countries in Africa, Asia and Europe, while the $H$. capsulatum var. farciminosum (HCF), produce equine disease known as Epizootic lymphangitis, which is reported in Africa, Asia and Europe, also affecting mules, asinine, camels and cattle, that they are contaminated by contact with fomites and soil, harboring 
spores of this fungus, his transmission can occur, through abrasions on the integument; for example by tick infestations as mechanical vectors. Moreover in humans, most affected patients have an asymptomatic course due to their immune response. $H$. capsulatum fail the lung epithelial cells expecting the host be immunocompromised for other diseases such as HIV, cancer, chronic alcoholism, and immunosuppressive drugs, for generating a reactivation of endogenous infection. There are no studies that report infections with the fungus, through water or food, nor transmission from person-person or animal-person. For now, eradicate the fungus from affected ecosystems is really difficult, all that remains is prevention and education to the population, for avoid the contamination with histoplasmosis, is recommended in people with immunosuppression, not assist to places that have been labeled as reservoirs of fungus as caves.

Keywords: Histoplasmosis, chiropterans, pigeon, occupational disease.

\section{RESUMO}

Histoplasmose ou citomicosis reticuloendothelial ou doença de Darling ou caverna, é causada pelo fungo Histoplasma capsulatum, que por falta de políticas de controle, tem apresentado altas taxas de morbidade e mortalidade em humanos e animais, afetando a produtividade do trabalho e criação de animais. Ele também provou ser uma crise global, por ignorância do método clínico, subestimando a importância da relação médico-paciente, e nenhum interrogatório. $O$ atividades de trabalho que predispõem à apresentação da doença são: speleologists, coletores de guano, mineração, trabalhadores rurais (biólogos e veterinários), que estão em contato direto com a manipulação de aves de capoeira ou esterco de galinha e os turistas que têm contato principalmente com cavernas, Atualmente são incluem pessoas que trabalham em terraplanagem, limpeza ou demolição de edifícios antigos e extração de madeira. $\mathrm{O}$. capsulatum tem três principais variedades que têm uma ampla distribuição geográfica e com elevado potencial patogénico que afecta os seres humanos e animais, encontrado para $H$. capsulatum var. capsulatum é endêmica na América e alguns países da África, Ásia e Europa, enquanto o $H$. capsulatum var. farciminosum (HCF), produz doença eqüina, 
conhecido como linfangite epizoótica, que é relatado na África, Ásia e Europa, afetando também mulas, asinino, camelos e gado, que estão contaminados pelo contato com fômites e do solo, abrigando esporos do fungo, sua transmissão pode ocorrer, através de abrasões na tegumento; por exemplo, infestações de carrapatos como vetores mecânicos. Além disso, em seres humanos, a maioria dos pacientes afectados ter um curso assintomático devido à sua resposta imunitária. H. capsulatum falha células epiteliais pulmonares esperando o anfitrião deste imunocomprometidos por outras doenças, como HIV, câncer, alcoolismo crônico, e drogas imunossupressoras, para gerar uma reactivação da infecção endógena. Não há estudos que relatam infecções com o fungo, através de água ou alimentos, nem a transmissão de pessoa-pessoa ou animal pessoa. Por agora, erradicar o fungo de ecossistemas afectados é realmente difícil, tudo o que resta é a prevenção e educação para a população, para evitar a poluição com histoplasmose, se recomenda em pessoas com imunossupressão, não assistir a lugares que são categorizados como reservatórios de fungos como cavernas.

Palavras-chave: histoplasmose, quirópteros, pomba, doença profissional.

\section{INTRODUCCIÓN}

La formación de nuevos ecosistemas está arraigada a la influencia del humano sobre diversas situaciones como: el aumento mundial de su población, globalización, migración de personas, exploración de nuevos territorios, que facilitan una interrelación más íntima con todos aquellos agentes que integran el ecosistema, y están ligados al cambio ambiental, deterioro de los hábitats naturales, migración de especies silvestres e introducción de animales exóticos, entre otros factores que promueven la alteración de la fauna nativa, afectándose el débil equilibrio entre el hombre y el ecosistema, lo cual favorece el incremento y adaptación de agentes infecciosos causantes de enfermedades zoonóticas como el caso de las micóticas que se pueden encontrar donde viven aves y quirópteros (Arias y Barrientos, 2002), lo que implica desafíos constantes al sistemas inmunológico del hombre y animal. 
Miller, (1997) afirmó que el 43.6\% de las enfermedades zoonóticas reconocidas hasta ese entonces estaban distribuidas por todos los continentes, afectando principalmente a África y Asia, seguido de Norteamérica, Suramérica, Europa y por último Centroamérica. En un estudio más reciente Fuentes et al., (2006) evaluaron los agentes responsables de las enfermedades zoonóticas: $45 \%$ tenían un origen viral, seguido por bacterias con un $28 \%$, parásitos $20 \%$ y hongos $7 \%$, por lo que se hace necesario determinar las estrechas relaciones entre la salud animal y la humana, poniendo de manifiesto un sinnúmero de oportunidades y desafíos a la profesión veterinaria.

En los últimos años, han tomado importancia las enfermedades de origen micótico, en primer lugar por las características propias de los agentes causales y su fácil asociación al ambiente y al humano, siendo uno de sus vehículos principales las heces de aves y quirópteros, y por otro lado, el creciente número de pacientes inmunodeficientes, ligado a la presencia de patologías como el VIH, así, como el uso de: 1) Quimioterapia ante el tratamiento de enfermedades malignas y 2) Fármacos inmunodepresores en el manejo de trasplantes de órganos (Arias y Barrientos, 2002), estos dos factores han favorecido la presentación de enfermedades zoonóticas micóticas.

Una de estas enfermedades es la causada por el hongo Histoplasma capsulatum, que por la falta de políticas de control y desconocimiento en el método clínico, donde se menosprecia la importancia de la relación médico-paciente, interrogatorio nulo y deficiente examen físico, ha empezado a mostrar altas tasas de morbi-mortalidad en humanos y animales, afectando la productividad laboral y zootécnica a nivel mundial (Muñoz et al., 2010). Es necesario convocar a la comunidad médica humana y animal, a observar y discutir inquietudes, porque de allí surge la investigación sobre los factores de riesgos que influyen en el desarrollo de estas enfermedades, y así poder frenar su crecimiento incontrolado, puesto que muchas de las estas son asintomáticas.

La ley de 1977 en su artículo 9 de la legislación cubana, definió a la enfermedad profesional, como una alteración de la salud patológicamente definida a causa de 
ejercer una actividad laboral, en ese mismo año se definió las sustancias y agentes presentes en el medio ambiente que eran capaces de originar una enfermedad profesional, listado emitido en el cual no se reportó la histoplasmosis. Once años más tarde, por medio del decreto 39 de 1988 se estipuló que toda enfermedad profesional debería ser reportada en un sistema de notificación obligatorio, proceso similar al que adoptó Argentina, pretendiendo afianzar la comunicación entre los actores de la salud como la Unidad Nacional de Salud Ambiental junto al médico laboral, con el fin de establecer la vigilancia, prevención y control de aquel nuevo riesgo para los trabajadores del área pecuaria. A comienzos de 1995 Cuba estableció un nuevo listado de agentes amenazantes para las labores profesionales, reflejada en la Resolución 2 de 1996, donde se incluyó la histoplasmosis, siendo de importancia, por sus constantes brotes epidémicos y gravedad en el cuadro clínico.

En el 2005, la Organización Internacional del Trabajo reunió en Nebraska al grupo de expertos en salud laboral, con el fin de actualizar la lista de este tipo de enfermedades que se han transmitido a los 85 países miembros entre ellos Colombia y la mayoría de países Americanos, la histoplasmosis no se incluyó desde un principio en la lista, consecuentemente Cuba apoyado únicamente por Chile formuló una petición donde pedía que se considerara a la histoplasmosis como una enfermedad laboral, pero esta opción no se tuvo en cuenta, y quizás es por ello que actualmente, la histoplasmosis cobra a diario vidas humanas, siendo categorizada como una enfermedad fantasma, y que se ha venido enfrentando con desconocimiento para su control.

\section{GENERALIDADES DE LA HISTOPLASMOSIS}

La histoplasmosis fue descrita por primera vez en 1906 durante la construcción del canal de Panamá por el médico Samuel Darling mediante necropsias, siendo identificado como un protozoario y diagnosticados como casos de Leishmaniosis, pues entonces se desconocía la existencia de la histoplasmosis (Canteros et al., 2005; Sánchez, 2009). Posteriormente, Da Rocha Lima, (1912) corrigió la clasificación taxonómica del agente, categorizándolo como un hongo; su primer 
aislamiento se logró en 1934 por De Monbreun mediante cultivos a partir de material clínico, unos años más tarde (1941) se aisló en Buenos Aires-Argentina, por primera vez el agente en Suramérica (Ulloa et al., 2006).

La histoplasmosis es también conocida como: citomicosis retículoendotelial (porque afecta éste orgánulo celular), enfermedad de las cavernas o de Darling (Acha y Szyfres, 2001). Diferentes estudios realizados han identificado diversas actividades laborales que predisponen a la presentación de la enfermedad tales como: espeleólogos, colectores de guano, mineros y trabajadores rurales que estén en contacto directo con las aves o manipulen pollinaza, así como turistas que tienen contacto con cuevas, actualmente se incluyen personas que trabajan en remoción de tierra, limpieza o demolición de viejas construcciones y tala de árboles; teniendo como factor común la perturbación de los microfocos (formados por aerosoles) (Kaufman, 2007; Muñoz et al., 2010) siendo favorecida la dispersión de las esporas conocidas como macroconidios (Figura 1) los cuales son esféricos de 8 a $14 \mu \mathrm{m}$ de diámetro presentando proyecciones digitiformes (Figura 2) con forma oval, de 1-4 por 2-6 $\mu \mathrm{m}$ de diámetro, que pueden estar unidos a los conidióforos (Sánchez, 2009) además de pequeños fragmentos de hifas que aprovechan las corrientes de aire, donde una vez inhalados estos cuerpos permiten establecer la enfermedad (Kaufman, 2007; Muñoz et al., 2010), puesto que, se ha comprobado experimentalmente que de uno a diez conidios pueden infectar a un ratón (Torres et al., 2000), y actualmente la enfermedad es reconocida como ocupacional (Acha y Szyfres, 2001; Fernández et al., 2010).

$H$. capsulatum es un hongo dimórfico, con una fase parasitaria que consiste en células de levadura (fase-Y), y una fase micelial sapróbica (fase-M). En cultivo, la transición de una fase a la otra puede revertirse por medio de regulación de la temperatura de incubación entre $25^{\circ} \mathrm{C}$ (micelio) y $37^{\circ} \mathrm{C}$ (levadura). Los micelios son encontrados en el suelo y nunca en tejidos infectados, en contraste a la Y-fase, la cual solo se presenta en pacientes (Maresca y Kobayashi, 1989). La mayoría de pacientes afectados tienen un curso asintomático debido a su respuesta inmunológica, y otros son sintomáticos debido a que su respuesta inmunológica es 
de tipo fungistático más no fungicida; la fase-Y intracelular del $H$. capsulatum aprovecha las células epiteliales pulmonares esperando que el hospedero se vea inmunocomprometido por otras enfermedades tales como $\mathrm{VIH}$, cáncer, alcoholismo crónico y fármacos inmunosupresores, para una reactivación endógena de la infección (Sánchez, 2009).

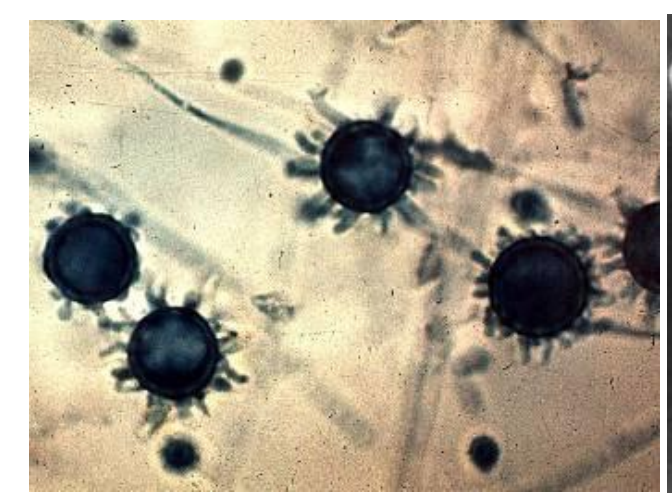

Figura 1. Macroconidios digitiformes en la M-phase $H$. capsulatum

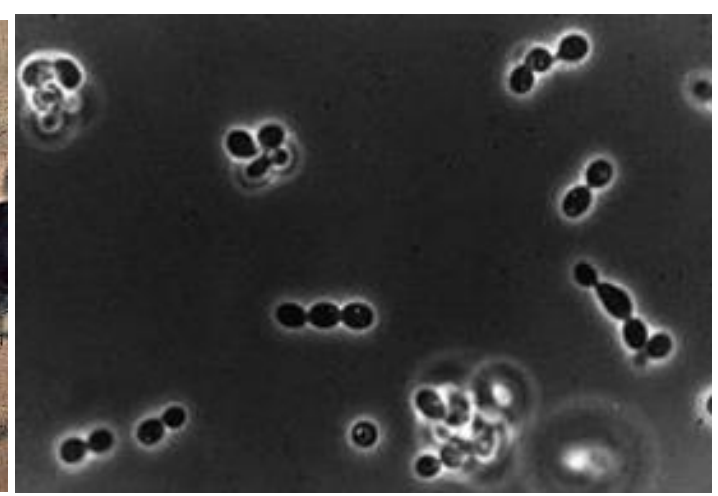

Figura 1. Fase levaduriforme de. H. capsulatum var capsulatum

Fuente: Sánchez, (2009).

\section{ETIOLOGÍA}

El dimorfismo de $H$. capsulatum se considera factor de virulencia (Acha y Szyfres, 2001; Sánchez, 2009; Muñoz et al., 2010) que favorece su adaptación, supervivencia y colonización en el animal; este microorganismo vive en el suelo (Ameni, 2006) y su clasificación taxonómica está en la Tabla 1; el microorganismo presenta tres variedades: var. Capsulatum, ureasa ${ }^{+}$, var. Farciminosium, de lento crecimiento y var. Duboisii, ureasa'.

Los microorganismos que han sido aislados del suelo y aquellos implicados en la infección humana se reproducen exitosamente, pero existe un bajo polimorfismo genético (Cáceres et al., 2012). Las tres variedades del $H$. capsulatum tienen una amplia distribución geográfica y poseen un alto potencial patogénico para humanos y animales (Torres et al., 2000), encontrándose que la variedad capsulatum es endémico en América y algunos países de África, Asia y Europa (Acha y Szyfres, 2001; Kaufman, 2007; Sánchez, 2009), mientras que la variedad farciminosum (HCF) ha sido reportada en África, Asia y Europa, y produce en 
equinos, mulares, asnales, camélidos y vacunos, la enfermedad conocida como linfangitis epizoótica, donde las esporas del hongo son transportadas por los animales infectados, contaminados por contacto directo con fómites y suelo (Acha y Szyfres, 2001; Kaufman, 2007). La entrada del agente puede darse a través de las heridas que ocasionan las infestaciones de garrapatas como vectores mecánicos, se ha confirmado que la contaminación de humanos y caninos posiblemente por compartir el espacio con caballos que fueron infectados con HCF (Ameni, 2006; Ueda et al., 2003).

Tabla 1. Clasificación taxonómica del $H$. capsulatum

\begin{tabular}{ccc}
\hline Reino & Fungi \\
Subreino & Dikaryomicota \\
Filo & Ascomicota & \\
División & Ascomycota & \\
Clase & \multicolumn{3}{c}{ Eurotiomycetes } \\
Orden & Onygenales \\
Familia & Onygenaceae & Anamorfo \\
Estado & Teleomorfo & Histoplasma \\
Género & \multicolumn{3}{c}{ Emmonsiella Ajellomyces } & Capsulatum (estadio \\
Especies & Capsulata (estadio reproductivo & reproductivo asexual) \\
\hline
\end{tabular}

La fase-M, es de tipo saprófita, filamentosa de carácter geofílico, puesto que vive en diferentes tipos de suelos preferencialmente los ácidos con concentraciones elevadas de $\mathrm{Ca}^{++}$(155.7-280.9 miliequivalentes $(\mathrm{mEq}) / 100 \mathrm{~g}$ ) y moderadas de $\mathrm{Mg}^{++}$ (32.9-88.6 $\mathrm{mEq} / 100 \mathrm{~g}$ ) siendo un hongo termo-nutricional porque sólo en ambientes tropicales y subtropicales prospera. Prefiere espacios de recintos cerrados como cuevas, grutas, minas y edificios desalojados (Sánchez, 2009), debido a que son sitios oscuros con temperaturas entre 25 y $32.2^{\circ} \mathrm{C}$ (Ulloa et al., 2006), sus procesos de esporulación se ven favorecidos por la presencia de oxígeno y materia orgánica (0.62-78.1\%), también se considera zoofílico porque afecta y depende de un sinnúmero de animales (López, 2005), en ambientes muy 
húmedos con más de $40^{\circ} \mathrm{C}$ se disminuye su desarrollo entre 75.2 a 100\% (Ameni, 2006 y Cáceres et al., 2012).

Estudios realizados en cuevas de México, donde conviven diversas especies de murciélagos, determinaron que éstos microambientes cumplen con todos los parámetros que requiere $H$. capsulatum para su desarrollo (Ulloa et al., 2006), también, los espacios abiertos se consideran óptimos para la subsistencia de la fase micelial, debido a que pueden estar contaminados con guano de murciélagos, gallinas, palomas u otras aves, lo cual contribuye a su diseminación (López, 2006; Sánchez, 2009), pero en los últimos años esta condición ha sido reevaluada, puesto que un estudio realizado en 2001 a un grupo de 250 estudiantes norteamericanos que visitaron un hotel en remodelación en México (Acapulco), resultaron todos con cuadros clínicos compatibles con histoplasmosis, de los cuales $60 \%$ de ellos fueron positivos, informándose al centro de control de enfermedades (CDC, Atlanta EEUU) (UNAM, 2013) concluyendo que la infección se adquirió en sitios diferentes que no tenían acumulación de guano de murciélagos ni aves (López, 2005; Sánchez., 2009).

Cabe resaltar que en la superficie del suelo y los primeros $20 \mathrm{~cm}$ de profundidad donde se encuentra material vegetal y residuos de animales se hallan microorganismos como: actinobacterias y hongos como el $H$. capsulatum (Garrido y Alvarado, 2010), los cuales son activados por la descomposición de la materia orgánica, siendo su fuente directa de nutrientes (Brömel y Sykes, 2005; Ulloa et al., 2006).

\section{HOSPEDEROS DE $\boldsymbol{H}$. capsulatum}

Las especies en las cuales este hongo puede completar su ciclo biológico son principalmente: paloma (Columba livia) y murciélagos (orden: Chiroptera). La paloma (Columba livia) se encuentran desde el nivel del mar hasta los 5000 msnm, en zonas templadas y tropicales, es una especie invasora en áreas urbanas y suburbanas (se observan en plazas, edificios y parques) debido en primer lugar a la destrucción sistemática de su hábitat, y en segundo, su 
capacidad de vuelo que favorece su migración (Lack, 2003; Gómez et al., 2005; Gottdenker et al., 2008). Su excremento contiene compuestos químicos como nitratos, sulfatos, sulfitos e hidrógenos de carbono, que sirven como medio de cultivo para el desarrollo y transmisión de diferentes agentes patógenos como protozoarios, hongos, bacterias, clamidias y virus, además sus nidos alojan piojos, hongos y bacterias (Dickx et al., 2010). Actualmente en pocos países de Europa y América consideran a la paloma como una plaga, por su impacto sobre la salud pública, donde se desarrollan programas para el control de su materia fecal, en Colombia aún no se estima dicho riesgo, porque esta ave se encuentra sin ningún control, en zonas urbanas, semiurbanas y rurales, e incluso en las islas del Caribe.

El murciélago (Chiroptera) debido a su etiología, tiene predilección por sitios oscuros como: cuevas, grietas de rocas, minas abandonas, oquedades de troncos, espacios entre las ramas de árboles y palmeras, alcantarillas, sótanos, paredes o techos de casas o edificios antiguos, entre otros (Teniente, 2008).

Taylor et al., (2005) afirmaron que la frecuencia de infección para un murciélago, está altamente correlacionada con la distancia que existe entre el suelo y el techo de la cueva, por lo cual, entre menor distancia de separación tengan estos dos elementos hay mayor probabilidad de infección para el murciélago, además su incidencia es directamente proporcional al tamaño de la colonia. Los murciélagos infectados con $H$. capsulatum desarrollan una relación comensal, adquiriéndolo por inhalación de los propágulos presentes en el ambiente (Canteros et al., 2005; Ulloa et al., 2006), donde posteriormente se evidenció un aislamiento del agente en el contenido intestinal de los murciélagos infectados, lo cual sugiere, que es a través de las heces como se elimina el hongo al ambiente. Actualmente, existen 38 especies de murciélagos en distintos países responsables de la diseminación de esta enfermedad, entre ellos Molossus molossus, Tadarida brasiliensis, insectívoros como Myotis californicus, Pteronotus parnelli, así como de nectívoros y polinívoros como Glossophaga soricina (Ulloa et al., 2006) pero el número de especies de murciélagos que diseminan el microorganismo se ha incrementado, relacionándolo con las migraciones locales y largas distancias que recorren, 
contribuyendo a la dispersión de las cepas del hongo (Sánchez, 2009; Cáceres et al., 2012).

Los humanos se han visto afectados por brotes en zonas urbanas, debido al uso de fertilizantes elaborados con guano de murciélagos y heces de aves, así como la invasión de estos animales en construcciones antiguas, implicando una estrecha asociación entre humanos inmunológicamente comprometidos (Acha y Szyfres, 2001), con la infección, lo que permite aumentar las probabilidades de contaminarse con otros hongos como criptococcos y candidas, para que finalmente adquieran la histoplasmosis, no es necesario tener presencia de los microfocos, pero tan solo algunos minutos de exposición, basta para que el humano se infecte, como en el caso que le sucedió en un grupo de estudiantes en México, quienes estuvieron alrededor de una hora en las afueras de una cueva y todos resultaron seriamente afectados (Fernández et al., 2010).

\section{FISIOPATOLOGÍA EN HUMANOS}

La histoplasmosis pulmonar primaria es la forma de presentación más común en personas inmunocompetentes (Sánchez, 2009), algunos pacientes que habitan en áreas endémicas, son asintomáticos, debido a que su sistema inmune está integro para combatir la infección, por lo tanto no requieren tratamiento (Cáceres et al., 2012). En la histoplasmosis pulmonar aguda, la persona tiene fiebre intermitente, tos, cefalea, dolores musculares y en tórax (Sánchez, 2009). No se observan en la mayoría de pacientes alteraciones torácicas cuando se hacen prueba radiológicas, pero en algunos casos se logra visualizar pequeños infiltrados, con un aumento en el volumen de ganglios linfáticos hiliares y mediastínicos (Acha y Szyfres, 2001). En las pruebas hemáticas, se aprecia cierto grado de anemia y moderada leucopenia, aunque en otros casos, se observa leucocitosis, en los cuales se requieren tratamiento (Tobón, 2012).

La histoplasmosis pulmonar cavitaria, que es grave, afecta principalmente a personas mayores de 40 años, en casos preexistentes de otras enfermedades pulmonares, teniendo una sintomatología similar a la tuberculosis (Acha y Szyfres, 
2001), además existe tos severa, expectoraciones abundantes, fiebre alta e intermitente (Sánchez, 2009), fibrosis progresiva con formación de cavidades en los lóbulos superiores, presentándose hemoptisis (Tobón, 2012). El proceso de la enfermedad, puede durar meses o años, y en algunos casos, la curación es espontánea (Acha y Szyfres, 2001); finalmente la histoplasmosis diseminada progresiva, es la presentación más común en personas inmunocomprometidas, enmarcada en un crecimiento incontrolado del hongo en diversos órganos (Cáceres et al., 2012), debido a las fallas en los mecanismos defensivos del hospedero, se ha observado que más del $90 \%$ de los casos reportados son atribuidos al virus de la inmunodeficiencia humana $(\mathrm{VIH})$, además, algunas veces no se evidencian alteraciones radiográficas del tórax, y los pocos casos en que sí, se observan infiltrados intersticiales 0 de tipo extensivo miliar, teniendo manifestaciones de la enfermedad en formas aguda, subaguda y crónica (Tobón, 2012; Sánchez, 2009).

En el ambiente $H$. capsulatum existe como un moho, contenido en el polvo principalmente de áreas contaminadas con guano o heces, la inhalación de los conidios es la primera vía de infección para el hombre, antes de 1970 se consideraba que las únicas rutas de entradas eran digestiva y cutánea. Una vez ha ingresado el microorganismo, se pone a prueba la primera línea de respuesta, que es el tejido linfoide asociado a la mucosa del sistema respiratorio superior (Acha y Szyfres, 2001), una vez superada esta defensa, el hongo logra establecerse en el tracto respiratorio inferior con la subsecuente infección pulmonar (Cáceres et al., 2012), generando un daño acentuado en alvéolos y bronquiolos, con posterior deterioro progresivo de la función pulmonar, donde se presenta la transición dimórfica al morfotipo fase-Y (levadura), durante las primeras horas de interacción con el parénquima pulmonar (Figura 3) (Garrido y Alvarado, 2010; Cáceres et al., 2012; Sahaza et al., 2014).

La respuesta inmune respiratoria contra hongos desarrollada por el hospedero es de tipo fungistático y no fungicida, primero, la inmunidad innata da el reconocimiento por parte de las células epiteliales, mediante la unión de 
inmunoglobulinas con la adhesina (proteína producida por el hongo para adherirse efectivamente al hospedero) Hsp 60, la cual es una proteína perteneciente a la familia de las Chaperoninas, cuya función principal es ayudar al plegamiento de otras proteínas recién sintetizadas (Sahaza et al., 2014), el hongo seguidamente enfrenta las defensinas (péptidos con función biosida natural contra bacterias, hongos y virus) como las proteínas surfactantes tipo A y D, producidas por los neumocitos tipo II, las cuales fomentan un aumento en la permeabilidad de la pared celular de la fase-Y (levadura), con el objetivo de disminuir así el crecimiento e internalización de la carga fúngica a los macrófagos (Arango et al., 1990); segundo, la inmunidad adquirida involucra la activación de células T y sus subpoblaciones como $\mathrm{CD}^{+}$(linfocito $\mathrm{T}$ colaborador), Th1 (linfocito T colaborador que se ha diferenciado en efector, y activa macrófagos mediante la producción de interferón Gamma), Th17 (linfocito T colaborador que se ha diferenciado en efector, y segrega interleucinas 17 y 22, que son los principales medidores de algunas reacciones alérgicas) y $\mathrm{CD}^{+}$(linfocito $\mathrm{T}$ citotóxico), quienes a su vez producen citoquinas como el interferón Gamma (IFN- $\gamma$ ), factor de necrosis tumoral Alfa (TNF- $\alpha$ ), interleucina 1b (IL1b) e interleucina 17 (IL17), estas 2 últimas promueven la migración de linfocitos implicados en el proceso y presentación de antígenos $(\mathrm{Ag})$ a las células $\mathrm{T}$ (linfocitos $\mathrm{T}$ ), asesinas naturales (NK) y linfocitos citotóxicos $\left(\mathrm{CD}^{+}\right)$, con la resultante quimiotaxis de macrófagos y neutrófilos para reforzar el proceso de fagocitosis y activación de gránulos que fomentan explosiones oxidativas principalmente en los espacios alveolares.

La interacción hongo-macrófago está dada por la subfamilia de integrina b2, que es una glicoproteína que participa en la unión de las células con otras células, y está ampliamente distribuida en la superficie de neutrófilos, macrófagos alveolares y monocitos, siendo los macrófagos las células de predilección para éste hongo, porque en su superficie existe un enriquecimiento de glicoproteínas con residuos D-b-galactosyl (radical glicosil de la galactosa), los cuales son reconocidos por diversos tipos de lectinas de la fase-Y (levadura), la cual con prontitud se une a estos residuos galactosados (Sahaza et al., 2014), y así permitir la internalización del hongo (Duarte et al., 2003). 


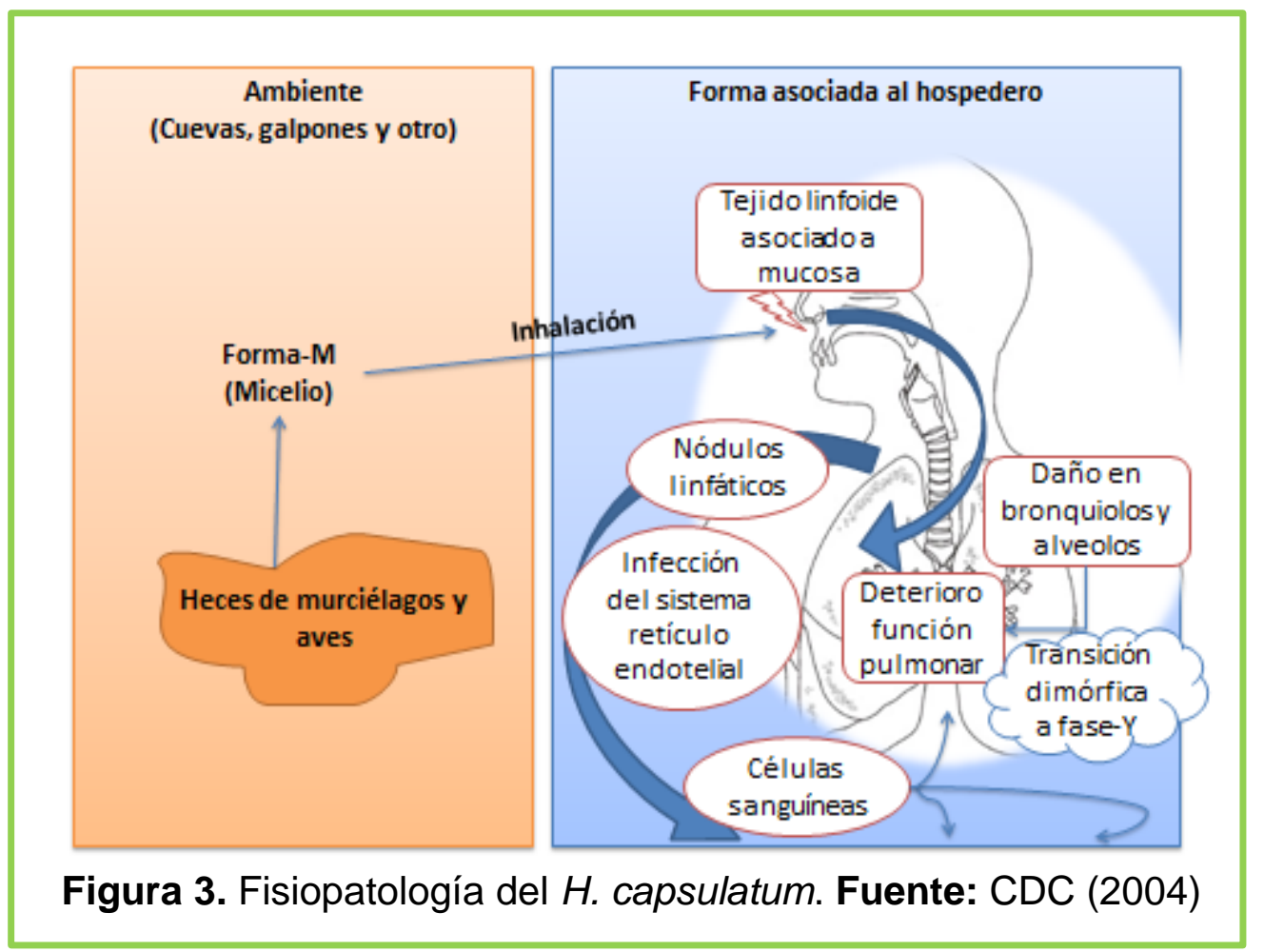

Una vez internalizado, en el fagolisosoma se ejecuta la inmunoxidación a través de metabolitos oxidativos como peróxido de hidrogeno $\left(\mathrm{H}_{2} \mathrm{O}_{2}\right)$, llegando a producir una oxidación celular, con propiedades antifúngicas (Arias y Barrientos, 2002); pero la fase- $Y$ (levadura) genera mecanismos de resistencia por medio de especies reactivas de oxigeno (ERO) donde degradan con enzimas el $\mathrm{H}_{2} \mathrm{O}_{2}$ (Arias y Barrientos, 2002; Brömel y Sykes, 2005; Sánchez, 2009), además el hongo manipula el pH de éste ambiente por medio de su bomba de protones, impidiendo que descienda a menos de 6.0, evitando así la activación de proteasas y demás enzimas hidrolíticas (Sánchez, 2009), posteriormente se inicia la síntesis y liberación de sideróforos del ácido hidroxámico por parte del hongo, para ayudar a atrapar el $\mathrm{Fe}^{++}$proveniente de la transferrina, utilizándolo como cofactor para varias metaloenzimas como ribonucleótido reductasa y succinato deshidrogenasa, las cuales participan en la actividad redox ya mencionada (Sahaza et al., 2014).

Otro factor de virulencia es el secuestro de $\mathrm{Ca}^{++}$intracelular, ejecutada por la proteína ligadora de calcio CBP1, en su fase-Y (levadura); y su último factor de virulencia, es la mutación (ausencia) del patrón molecular asociado a patógenos (PAMP) a1-3 glucano (polisacárido constituyente de la pared celular de hongos 
patógenos respiratorios), evadiendo y pasando inadvertido frente a la inmunidad hospedera, considerándolo como el mejor mecanismo para aguardar en las células epiteliales, puesto que se ha comprobado que la cepa tradicional rugosa (R) (con a1-3 glucano) prospera en cultivos sólidos, generando colonias rugosas que destruyen el fagocito, mientras que la forma mutante denominada cepa lisa (S) prospera en cultivos líquidos generando colonias lisas, que persisten dentro del macrófago al menos por tres meses sin llegar a afectarlo (López , 2013).

La fagocitosis del hongo por parte de los macrófagos, no es garantía de su destrucción, por el contrario sirve de vehículo para viajar en un término de 14 a 21 días después de la primera infección, a todo el sistema retículo endotelial (SER), además permite la gemación constante dentro del fagolisosoma (Acha y Szyfres, 2001; Garrido y Alvarado, 2010), y así el hongo puede pasar al citoplasma de células adyacentes, siguiendo su multiplicación deliberadamente (Figura 3).

Las citoquinas pro-inflamatorias generan como resultado final una respuesta inflamatoria-granulomatosa compartida con focos de caseificación y necrosis, formando calcificaciones llamadas histoplasmonas que son la lesión definitiva, estas miden cerca de 2 a $3 \mathrm{~mm}$ con una cápsula de $1 \mathrm{~mm}$ de espesor, los órganos afectados son los ganglios linfáticos y pulmón, posteriormente por diseminación hematógena invaden al hígado, bazo y tejido mucocutáneo (Figura 3); éstas histoplasmomas no dejan de crecer porque persisten los antígenos ( $\mathrm{Ag}$ ) del granuloma, con un asentamiento constante de colágeno y fibrosis, aumentando su espesor hasta erosionar el órgano implicado (Cáceres et al., 2012).

\section{FISIOPATOLOGÍA EN ANIMALES}

El papel de los animales domésticos y silvestres, en la epidemiología es similar a la del hombre, son hospederos accidentales de $H$. capsulatum, a pesar de ser altamente susceptibles a la infección sistémica natural no participan en el mantenimiento o en la transmisión de la enfermedad. Se han realizado constantes aislamientos del hongo en diversos órganos de ratas, ratones, roedores silvestres (Proechimys guyanensis), perezosos, hurones y zorrillos (Acha y Szyfres, 2001), 
pero pocos son los resultados obtenidos al intentar infectar animales de manera experimental, por lo tanto, se cree que el punto crítico no son los animales sino el sitio de sus deposiciones (Ameni, 2006).

En équidos y vacunos la incidencia de la enfermedad es directamente proporcional a la densidad poblacional, el hongo toma varias formas dependiendo de su vía de entrada por: 1) Tegumentos, se presenta por disposición de lesiones de piel ocasionadas por picaduras de garrapatas, que entran en contacto con secreciones contaminadas con esporas, con lo cual se puede apreciar lesiones nodulares, pustulosas y ulcerosas que producen dolor; 2) Conjuntiva, siendo los vectores moscas del género Musca o Stomoxys, demostrado por Gabal y Hennager, (1983) quienes aislaron el microorganismo del tracto gasto-intestinal de éstas moscas; 3) Pulmonar, es poco frecuente y sólo ocurre por inhalación del hongo (Ameni, 2006); sea cual sea su forma de presentación, por lo general se aprecia, pérdida progresiva de la condición corporal y poco apetito.

En caninos y felinos, hay cuatro formas de presentación de la enfermedad: 1) Clínica, 2) Subclínica (Brömel y Sykes, 2005), 3) Respiratoria primaria (Acha y Szyfres, 2001) o granulomatosa pulmonar (histoplasmosis pulmonar aguda), en la que los animales enfermos tienen tos, fiebre y anorexia (Brömel y Sykes, 2005); y 4) Histoplasmosis diseminada progresiva (HDP), se manifiesta en perros jóvenes y gatos (menores de 1 año de edad) con infección previa del virus de la leucemia viral felina (FeLV) (Acha y Szyfres, 2001), y sus signos clínicos son debilidad, letargia, emaciación, fiebre, taquipnea, sibilancias, tos crónica acompañada de linfoadenopatías hiliares generando obstrucciones parciales en los bronquios principales, ocasionando disnea, estornudos, jadeo, lesiones oculares, cojera en uno o más de sus miembros por artralgias, así como también hinchazones en sus miembros por artralgias e inflamaciones, evidenciando procesos de osteomielitis con reacciones endóstales, mucosas ictéricas, vómito, dolor abdominal, diarreas con hematoquecia o melena, engrosamiento y ulceración de nódulos cutáneos. Cuando se hacen radiográficas de tórax, las lesiones son escasas, siendo difusas e infiltrándose en alveolos por medio de procesos neurológicos como los 
nistagmos verticales (Brömel y Sykes, 2005), en el cuadro hemático se puede observar una anemia leve no regenerativa de carácter normocrómico-normocítico, mientras los cambios leucocitarios dependen del curso de la enfermedad, siendo más común la leucopenia que la leucocitosis (neutrofilía) y trombocitopenia tal vez por un aumento en el consumo o secuestro de plaquetas (Jubb et al., 1991).

\section{DIAGNÓSTICO}

Para el diagnostico de esta enfermedad se utiliza los siguientes mecanismos: intradermorreacción cultivos microbiológicos, métodos colorimétricos, pruebas serológicas y moleculares.

La intradermorreacción es un método para establecer con certeza la situación epidemiológica, además de evaluar la existencia de una inmuno-competencia, para lo cual se emplea el antígeno (Ag) micelial histoplasmina al 1\%, inoculando al paciente $0,05 \mathrm{ml}$ en la región antebraquial anterior, leyendo el resultado a las 48 horas después (Torres et al., 2000). La prueba ofrece la ventaja de tener una sensibilidad independiente al cuadro de infección, como desventajas cabe resaltar que la sensibilidad se establece a partir de 1 a 2 meses después de la primoinfección (Sánchez, 2009), no discrimina una infección reciente de una antigua y se presentan reacciones cruzadas con la coccidioidina y blastomicina (Torres et al., 2000; Acha y Szyfres, 2001).

Los cultivos microbiológicos son la principal prueba de diagnóstico de histoplasmosis, como material biológico se puede hacer en sangre, pulmón, médula ósea, orina (Acha y Szyfres, 2001), lesiones de piel, esputo (Arango et al., 2011), muestras de hígado, líquido pleural y líquido cefalorraquídeo (LCR) (Brömel y Sykes, 2005), tiene la desventaja de requerir condiciones especiales y personal capacitado en la manipulación del hongo (Muñoz et al., 2010), puesto que en una muestra contaminada no se diferencia cuando existe infección o es una colonización, siendo muy variables los valores de sensibilidad, además, se necesita mínimo 21 días para la fase-M (micelio) y 5 días para fase-Y (levadura), siendo ocho semanas, el plazo de lectura del cultivo para obtener resultados 
(Sánchez, 2009), el cultivo debe complementarse utilizando azul de lactofenol para el estudio microscópico de las características tuberculadas de las macroconidias e hifas septadas e hialinas (Zerpa et al., 2011).

Las pruebas colorimétricas son directas, se realizan con biopsias de: hígado, úlceras orofaríngeas, bazo, pulmón, ganglios linfáticos (Zerpa et al., 2011), glándulas suprarrenales, médula ósea, extendidos de sangre periférica, muestras con aguja fina de lesiones cutáneas y mucosas (Tkach et al., 2012), mediante el empleo de coloraciones especiales (Muñoz et al., 2010), como el plata metenamina de Grocott (Acha y Szyfres, 2001) donde se pueden evidenciar la fase-Y (levadura) intracelular pequeña de color marrón en el citoplasma de los macrófagos y demás células fagocíticas como los polimorfonucleares (PMN) 0 histiocitos (Muñoz et al., 2010; Zerpa et al., 2011). Las levaduras se observan libremente en los exudados piogranulomatosos, empleando coloraciones hematológicas (Muñoz et al., 2010) como la de Wright o Giemsa, y pueden confundirse con: Candida glabrata, Penicillium marneffei, Pneumocystis jirovecii antes conocido como Pneumocystis carinii, Cryptococus neoformans $y$ Blastomyces dermatitidis y Leishmania spp (Sánchez, 2009). La sensibilidad depende directamente de la forma clínica al momento de la toma de la muestra y la habilidad del observador (Restrepo et al., 2003; Muñoz et al., 2010).

Las pruebas serológicas tienen la desventaja de diagnosticar la enfermedad hasta la cuarta semana pos-infección, tiempo en el cual se producen los anticuerpos (Ac), siendo su sensibilidad dependiente del cuadro clínico de la enfermedad. Las pruebas más usadas son la inmunodifusión (ID) y la fijación del complemento (FC) (Sánchez, 2009). En la ID en gel agar, se observan 2 tipos de bandas gracias a la presencia de Ac específicos contra los antígenos $(\mathrm{Ag}) \mathrm{H}$ y $\mathrm{M}$, estos $\mathrm{Ag}$ son dos glicoproteínas obtenidos en los cultivos de fase-M (micelio) o fase-Y (levadura); el $\mathrm{Ag} \mathrm{H}$ es similar a la $\beta$-glucosidasa y cuando se detecta indica que la histoplasmosis está en pleno curso, el inconveniente es que se puede detectar en el $10 \%$ de los casos, mientras que el $\mathrm{Ag} \mathrm{M}$, es similar a una catalasa, y se observa en un $80 \%$ de las muestras, pero no determina si la histoplasmosis está activa, 
puesto que los Ac formados contra este Ag perduran hasta por 6 años, así el patógeno haya sido eliminado (Ulloa et al., 2006), siendo menos sensible que la fijación del complemento (FC) para humanos y animales (Brömel y Sykes, 2005), pero es más específica que esta misma sin importar la forma clínica por la que se esté cursando. La FC tiene como objetivo la identificación de Ac fijadores de complemento específicos contra el hongo presente en el suero o LCR, observándose que en el Ag histoplasmina para el análisis, los resultados de títulos de Ac entre 1:8 a 1:16, se consideran sugestivos de un posible contacto, mientras que títulos mayores a 1:32 indican una histoplasmosis activa (Muñoz et al., 2010).

En las pruebas moleculares se utiliza la reacción en cadena polimerasa (PCR) anidada, desarrollada Bialek et al., (2001) que tiene por objetivo detectar el DNA del $H$. capsulatum para lo cual se emplea de un gen llamado Hc100 que busca, detecta y amplifica un gen codificador de la proteína $100 \mathrm{KDa}$ única y específica para el hongo, cuenta con una sensibilidad y especificidad del 95 y 100\% respectivamente, mientras que para la PCR en tiempo real es de 77 y $100 \%$ respectivamente (Muñoz et al., 2010); su gran ventaja es que no revela resultados de reacciones cruzadas con otros agentes fúngicos ni bacterianos (Brömel y Sykes, 2005). Otros beneficios del uso de PCR es la posibilidad de establecer nuevas zonas endémicas y así ampliar los estudios epidemiológicos, también detecta el hongo en muestras fijadas en parafina, y en heces de aves y murciélagos, sin necesidad de que la muestra presente una cantidad considerable de carga fúngica para llegar a ser encontrada (Muñoz et al., 2010).

Para la detección de Ag, se utiliza: sangre, líquido alveolar, LCR y orina (Sánchez, 2009), siendo útil en los casos de histoplasmosis difusa progresiva, porque tiene alto grado de sensibilidad, teniendo en cuenta que la aclaración del Ag en orina es más lenta que en el suero (Garrido y Alvarado, 2010).

La prueba de ELISA que es un ensayo de inmunoabsorción ligado a enzimas, tiene varias ventajas, entre ellas la detección del Ag de tipo polisacárido de manera temprana y rápida sin importar baja concentración de Ac, establecimiento de un margen epidemiológico y la evolución al tratamiento (Muñoz et al., 2010; 
Cáceres et al., 2014). Las desventajas se deben a una reacción cruzada entre blastomicosis, paracoccidioidomicosis y peniciliosis, también el uso de antifúngicos enmascara la presencia de concentración de $\mathrm{Ag}$ debido a que se promueve una baja carga fúngica (Muñoz et al., 2010); y este tipo de pruebas aún no han sido aplicadas en pacientes caninos ni felinos (Brömel y Sykes, 2005).

\section{EPIDEMIOLOGÍA DE LA HISTOPLASMOSIS}

La histoplasmosis es señalada como un problema de salud pública (Gómez, 2011), debido a que la población afectada en su mayoría son pacientes $\mathrm{VIH}^{+}$, quienes tienen un acceso limitado a los servicios de salud, y las herramientas diagnósticas que se emplean en mayor grado arrojan resultados tardíos, alcanzando una mortalidad del 12 a 48\% (Cáceres et al., 2012). Por otro lado, la mayoría de países reportan escasos datos clínicos y epidemiológicos sin ninguna coherencia, a pesar del número elevado de pacientes con histoplasmosis en regiones endémicas y no endémicas; esto indica que las medidas de prevención, control y tratamiento presentan grandes dificultades para implementarse en dichos lugares (Gómez, 2011).

En la actualidad existe un sistema de vigilancia llamado Geo-Sentinel a nivel mundial, que incorpora diferentes clínicas y hospitales cuyo objetivo es hacer el seguimiento epidemiológico de los casos de micosis que afectan a los viajeros; esto ha permitido concluir que entre los años 1998 a 2002, la histoplasmosis fue la micosis que más afectó a turistas alcanzando un $70 \%$ de los casos, seguido por la coccidioidomicosis, en viajeros que provenían de Norteamérica, Centroamérica y Suramérica, lo cual se relacionó con el ecoturismo (visita a cuevas) en los países Centro y Sur América, por lo cual la histoplasmosis ahora está registrada y señalada en el "Health information for international travel yellow book" con una serie de recomendaciones para evitar la infección, además de referenciar las áreas altamente endémicas (Sánchez, 2009). 


\section{Situación mundial}

La histoplasmosis está distribuida en todo el mundo, aunque es más frecuente su presentación en el continente americano porque posee que en otros posee zonas endémicas de tal forma, que toda su población podría contraer la infección, mientras que en el continente Europeo y Asiático los casos en humanos son escasos (Acha y Szyfres, 2001; Sánchez, 2009). En México, el inicio de la histoplasmosis difusa progresiva fue considerada como una entidad rara, cambiando este panorama a partir de 1980, por el aumento de casos de individuos con inmunosupresión de diversos orígenes y afectados por ésta patología, lo que obligó a los sistemas de salud mexicanos a incluirla en el registro oficial de enfermedades infecciosas y vigilar la micosis, la incidencia de la enfermedad se incrementó entre los años 1991-1995, actualmente en el país no se tiene una visión clara de su vigilancia y control (Corcho, 2013).

En la década de 1990 en EEUU, la histoplasmosis fue la infección micótica sistémica de mayor recurrencia en pacientes con $\mathrm{VIH}^{+}$en lugares endémicos como: Valle de los ríos Ohio, Missouri y Mississippi, y su incidencia alcanzó 2 y 26.7\% (Sánchez, 2009; Acha y Szyfres, 2001; Cáceres et al., 2012), desarrollando el estadio de la enfermedad en su forma difusa progresiva, estimando que el $80 \%$ de la población (30 millones de personas) de estos lugares han tenido contacto alguna vez con el H. capsulatum (Acha y Szyfres, 2001; Sánchez, 2009). En los últimos años, las condiciones de trabajo en las empresas avícolas de EEUU han cambiado poco, a pesar de que se han informado sobre el alto riesgo que implica la ejecución de estas tareas, pues la mayoría de los galpones constan de suelos donde su base es la tierra siendo una condición que favorece mucho más la estancia del hongo en el suelo porque aumenta sus procesos de esporulación, que aunado a los sistemas de ventilación de dichas infraestructuras, se incrementa la diseminación del hongo, porque se volatilizan las esporas a grandes distancias (Construction Safety Council, 2012).

En Brasil, el hongo se presenta en la piel de pacientes con $\mathrm{VIH}^{+}$en comparación con EEUU, también, existen casos de la enfermedad en la forma en que afecta el 
tracto gastrointestinal (TGI) alcanzando una prevalencia del 10\%, los pacientes presentan dolor abdominal, diarrea, fiebre, obstrucción y ruptura de intestino delgado o el colon (Garrido y Alvarado, 2010); esto puede sugerir diferencias genéticas del hongo entre regiones, reflejada en la patogenia (dermatotropismo) con lesiones muco-cutáneas alcanzando el 44\% (Gómez, 2011). En Venezuela, en estudios retrospectivos efectuados entre los años 2000 a 2005, de una muestra de 158 casos de histoplasmosis el $34 \%$ eran portadores de $\mathrm{VIH}^{+}, 13 \%$ otras enfermedades malignas, $12 \%$ tenían contacto con aves de corral, $10 \%$ eran menos de 2 años de edad y un 7\% mayores de 65 años. En Guyana Francesa, estudios del mismo tipo identificaron pacientes con $\mathrm{VIH}^{+}$que presentan infecciones concomitantes con histoplasmosis (frecuencia de 15.4 por cada 1000 pacientes/año), seguido de la candidiasis esofágica, toxoplasmosis cerebral y por último la tuberculosis (Gómez, 2011).

Las regiones de la Pampa, Río de la Plata y Buenos Aires en Argentina, son consideradas zonas endémicas, la incidencia alcanza un 22,4 a $53,6 \%$ en pacientes inmuno-competentes, y con $\mathrm{VIH}^{+} 6 \%$ a $7 \%$ (Sánchez, 2009), sin embargo igual que en la mayoría de países los procesos para identificación del hongo demandan altos costos por su complejidad (Toranzo et al., 2009).

En Cuba 1965, se reportaron los primeros brotes epidémicos de histoplasmosis, donde es considerada la micosis sistémica y oportunista más frecuente de ese país, esta enfermedad se observó en trabajadores y empleadores de cuevas y minas, quienes realizaban actividades que alteran el suelo con excavaciones o sitios de refugio para murciélagos y aves, trabajos ejercidos sin protección en vías respiratorias, por lo que se consideró la histoplasmosis como una enfermedad de tipo profesional, con declaración obligatoria ante las autoridades sanitarias (Fernández et al., 2010; Gómez, 2011).

\section{Situación en Colombia}

La histoplasmosis tiene una elevada frecuencia de presentación en Colombia, pero su incidencia real e impacto en la salud pública es desconocida; no existen 
en la actualidad políticas de control, porque no se considera una enfermedad de declaración obligatoria, siendo así que las cifras de incidencia son difíciles de calcular, aunque tratando de llegar a una aproximación de la epidemiología, se diseñó la encuesta nacional para la vigilancia de la histoplasmosis, con la finalidad de recopilar los datos existentes entre 1992 a 1997 y otra encuesta realizada entre 2005 a 2008, con información de pacientes diagnosticados clínicamente con histoplasmosis, en 20 departamentos del país (Figura 4).

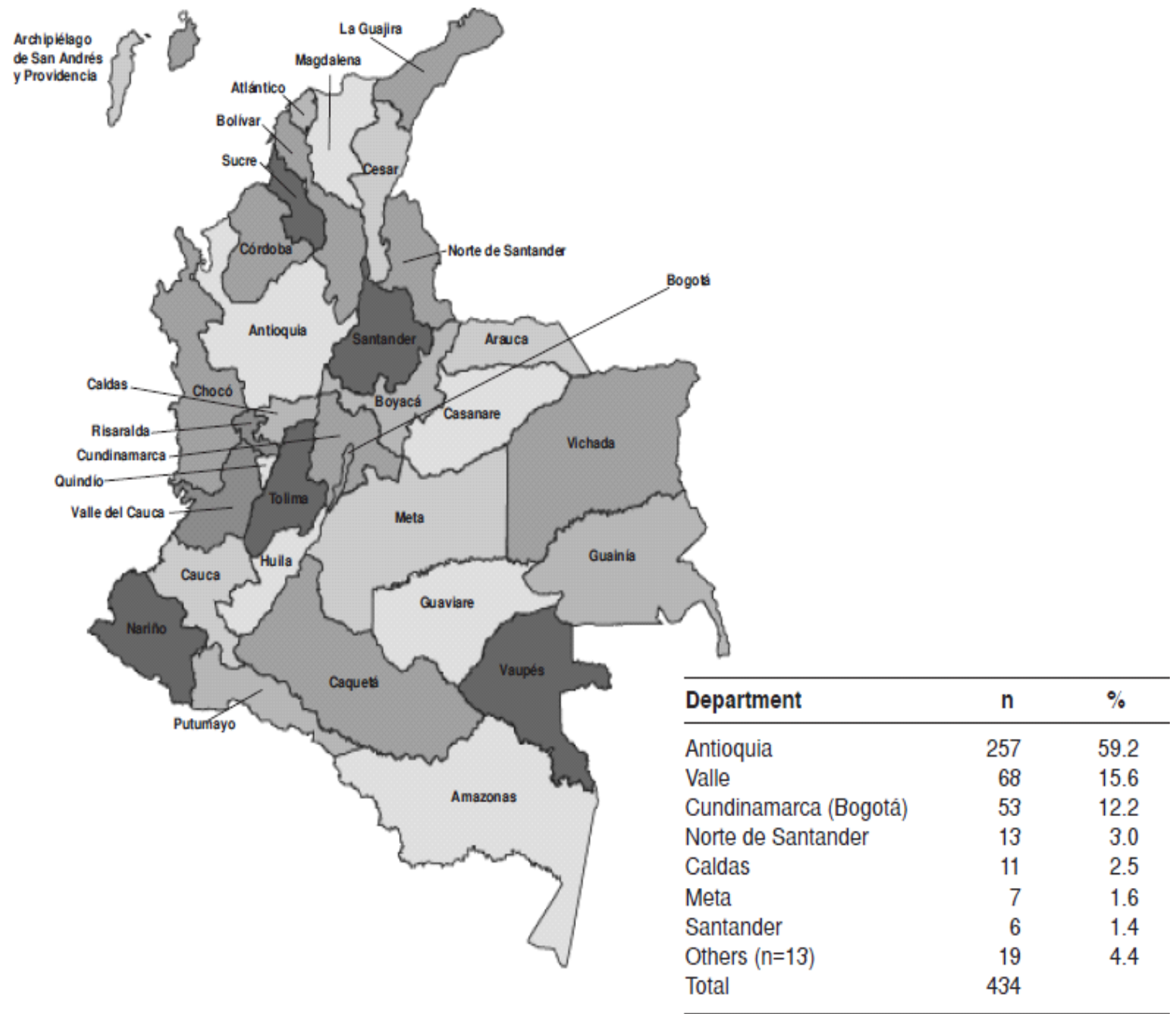

Figura 3. Histoplasmosis en Colombia. Fuente. Arango et al., (2011)

El $87 \%$ de los reportes provenían de los principales departamentos: Valle, Antioquia y Cundinamarca, en el último periodo del estudio (2005-2008) se observó un incremento cinco veces mayor de la enfermedad en comparación con 
el primer periodo del estudio (1992-1996) (Arango et al., 2011), se encontró que un $3.9 \%$ eran niños menores de 15 años mientras que $96.1 \%$ eran adultos, con predominio del género masculino (77\%) y edad promedio de 38 años, de los cuales $70.5 \%$ eran portadores de $\mathrm{VIH}^{+}$, por último, un $7 \%$ presentaban otro tipo de inmunosupresión causada por el uso de esteroides, neoplasias, diabetes, cirrosis, alcoholismo y malnutrición, trasplantes de órganos (Muñoz et al., 2010; Cáceres et al., 2012; Arango et al., 2011; Gómez, 2011). Existe evidencia que la donación de un órgano contaminado a un organismo receptor es otra forma de contaminación (Gómez, 2011; CDC, 2004).

\section{ANÁLISIS CRÍTICO}

Muchos vacíos quedan este tema, lo que genera un gran número de oportunidades de investigación entre ellos ¿por qué se encuentra en murciélagos el hongo?, otra situación de pregunta ronda al hecho de ¿cómo es la interacción del microorganismo con el sistema inmune del murciélago hasta la eliminación por sus heces?

A pesar de que el auge de ésta enfermedad está directamente ligada con la población de quirópteros, no debe olvidarse que éstos últimos tienen una importancia relevante en el mantenimiento de los ecosistemas (Teniente, 2008), por ejemplo los murciélagos insectívoros tienen un consumo mínimo de 500 insectos/hora, los polinívoros dispersan aproximadamente 5 semillas $/ \mathrm{m}^{2}$ en bosques talados, estableciendo fenómenos de quiropterofilia-quiropterocoria especialmente de especies arbustivas importantes para la vida cotidiana del hombre tales como las de los generos Piper, Solanum y Cecropia; siendo así que el objetivo de éste escrito no es precisamente estigmatizar la existencia de los quirópteros, sino que se invita a reconocer los factores de riesgo de la enfermedad y buscar mecanismos de eliminación del hongo, aunque es difícil, o de controlar con mayor eficacia el hongo. 


\section{CONCLUSIONES}

No existen estudios que reporten infecciones de histoplasmosis transmitidas a través del abastecimiento de agua o alimento, ni tampoco de la forma personapersona, o animal-persona.

Por el momento, erradicar el hongo de los ecosistemas afectados, es realmente difícil, lo único que queda es prevención y educación a la población. El mejor método para la prevención de la histoplasmosis, especialmente en personas con una inmunodepresión, es no asistir a lugares que sean catalogados como reservorios del hongo.

El tiempo que toma el diagnóstico, juega un papel crucial en la sobrevivencia de los pacientes, actualmente los métodos más eficaces en tiempo, sensibilidad y especificidad, son empleados de una forma centralizada por laboratorios privados, donde la mayoría de pacientes afectados se ven limitados por el factor económico.

Los veterinarios y biólogos son una importante población de riesgo en la adquisición de la enfermedad, porque constantemente comparten espacios que favorecen el crecimiento del hongo (galpones, cuevas y otros).

\section{REFERENCIAS BIBLIOGRÁFICAS}

1. Acha PN, Szyfres B. Zoonosis y enfermedades transmisibles comunes al hombre y a los animales. Vol. 1: Bacteriosis y Micosis. Publicación Científica y Técnica, N. 580. 3르 ed. Organización Panamericana de la salud, Washington, DC. p 366-377. 2001.

2. Ameni G. Epidemiology of equine histoplasmosis (epizootic lymphangitis) in carthorses in Ethiopia. The Veterinary Journal, 172 (1): 160-165. 2006.

3. Arango M, Cano LE, De Bedout C, Estrada S, Gómez I, Franco L, Jaramillo E, Muñoz C, Naranjo MS, Orozco B, Ramírez R, Tabares A, Velásquez G, Restrepo A. Histoplasmosis y criptococosis diseminada en pacientes con el síndrome de inmunodeficiencia adquirida (SIDA). Acta Médica Colombiana, 15 (2): 84-91. 1990.

4. Arango M, Castañeda E, Agudelo C, De Bedout C, Agudelo CA, Tobón A, Linares M, Valencia Y, Restrepo A. Histoplasmosis: results of the Colombian National Survey, 1992-2008. Biomédica, 31 (3): 344-356. 2011.

5. Arias R, Barrientos E. Reacciones adversas a la anfotericina $B$ en pacientes VIH (+) con diagnóstico de micosis sistémica. Tesis pregrado Químico Farmacéutico, Universidad Nacional Mayor de San Marcos, Facultad de Farmacia y Bioquímica, Lima, Perú. 73 p. 2002. 
6. Bialek R, Fischer J, Feucht A, Najvar L, Dietz K, Knobloch J, Graybill JR. Diagnosis and monitoring of murine histoplasmosis by a nested PCR assay. Journal of Clinical Microbiology, 39 (4): 1506-1509. 2001.

7. Brömel C, Sykes J. Histoplasmosis in dogs and cats. Clinical Tehniques in Small Animal Practice, 20 (4): 227-232. 2005.

8. Cáceres DH, Gómez BL, Restrepo A, Tobón A. Histoplasmosis y sida: factores de riesgo clínicos y de laboratorios asociados al pronóstico de la enfermedad. Infectio, 16 (3): 44-50. 2012.

9. Cáceres D, Scheel CM, Tobón A, Ahlquist A, Restrepo Á, Brandt M, Chiller T, Gómez B. Validation of an enzyme-linked immunosorbent assay that detects Histoplasma capsulatum antigenuria in Colombian patients with AIDS for diagnosis and follow-up during therapy. Clinical and Vaccine Immunology, 21 (9): 1364-1368. 2014.

10. Canteros CE, lachini RH, Rivas MC, Vaccaro O, Madariaga J, Galarza R, Snaiderman L, Martínez M, Paladino M, Cicuttin G, Varela E, Zuiani F, Sahaza JH, Tylor ML, Davel G. Primer aislamiento de Histoplasma capsulatum de murciélago urbano Eumops bonariensis. Revista Argentina de Microbiología, 37 (1): 46-56. 2005.

11. Centro de control y prevención de enfermedades (CDC - Centers for Disease Control and Prevention). Biology of histoplasmosis. 2004. Recuperado 07 Septiembre de 2015. Disponible En: http://www.cdc.gov/niosh/docs/2005109/pdfs/2005-109FS-sp.pdf

12. Construction Safety Council. Health hazard in construction workbook. Chicago, Estados Unidos, 247 p. $2012 . \quad$ Disponible En: https://www.osha.gov/dte/grant materials/fy09/sh-1949509/health hazards workbook.pdf

13. Corcho A, Muñoz B, Palma G, Ramírez A, Martínez M, Frías $M$, Reyes $M$, Martínez E, Manjarrez M, Alfaro L, Higuera A. Brote inusual de histoplasmosis en residentes del estado de México. Gaceta Médica de México, 147 (5): 377-384. 2011.

14. Dickx V, Geens T, Deschuyffeleer T, Tyberghien L, Harkinezhad T, Beeckman DS, Braeckman L, Vanrompay D. Chlamydophila psittaci zoonotic risk assessment in a chicken and turkey slaughterhouse. Journal of Clinical Microbiology, 48 (9): 32443250. 2010.

15. Duarte E, Zenteno E, Taylor M. Interaction of Histoplasma capsulatum yeasts with galactosylated surface molecules of murine macrophages. Archives of Medical Research, 34 (3): 176-183. 2003.

16. Fernández CM, Martínez G, Illnait MT, Perurena MR, González L. Brotes de histoplasmosis ocupacional en la provincia La Habana. Revista Cubana de Medicina Tropical, 62 (1): 68-72. 2010.

17. Fuentes M, Pérez L, Suárez Y, Soca M, Martínez A. La zoonosis como ciencia y su impacto social. REDVET Revista Electrónica de Veterinaria, 7 (9): 1-19. 2006.

18. Gabal MA, Hennager S. Study on the survival of Histoplasma farciminosum in the environment/experimentelle untersuchungen zur lebensfähigkeit von Histoplasma farciminosum. Mycoses, 28 (9): 481-487. 1983.

19. Garrido EJ, Alvarado JL. Caracterización clínica y epidemiológica de los pacientes con diagnóstico de histoplasmosis y criptococcosis con el síndrome de inmunodeficiencia adquirida-SIDA. Tesis de Pregrado Médico Cirujano, 
Universidad de San Carlos de Guatemala, Facultad de Ciencias Médicas, 86 p. 2010.

20. Gómez B. Histoplasmosis: Epidemiology in Latin America. Current Fungal Infection Reports, 5 (4): 199-205. 2011.

21. Gómez H, Oliveras A, Medellín R. Columba livia. Vertebrados superiores exóticos en México: diversidad, distribución y efectos potenciales. Instituto de Ecología, Universidad Nacional Autónoma de México. Bases de datos SNIB-CONABIO. Proyecto U020. México. D.F. 6 p. 2005. Disponible En: http://www.conabio.gob.mx/conocimiento/exoticas/fichaexoticas/Columbalivia00.p $\underline{\mathrm{df}}$

22. Gottdenker N, Walsh T, Jiménez G, Betancourt F, Cruz M, Soos C, Miller E, Parker P. Causes of mortality of wild birds submitted to the Charles Darwin Research Station, Santa Cruz, Galápagos, Ecuador from 2002-2004. J. Wildlife Dis., 44 (4): 1024-1031. 2008.

23. Jiménez RA, Urán ME, De Bedout $C$, Arango M, Tobón AM, Cano LE, Restrepo A. Brote de histoplasmosis aguda en un grupo familiar: identificación de la fuente de infección. Biomédica, 22 (1): 155-159. 2002.

24. Jubb K, Kennedy P, Palmer N. Patología de los animales domésticos. $3^{\mathrm{a}} \mathrm{Ed}$. Editorial Agropecuaria Hemisferio Sur, Montevideo, Uruguay. Tomo 3: p 236-238, Tomo 2: p 191 y Tomo 1: p 439. 1991.

25. Kasuga T, White TJ, Koenig G, McEwen J, Restrepo A, Castañeda E, Da Silva C, Heins EM, De Freitas RS, Zancopé RM, Qin Z, Negroni R, Carter DA, Mikami Y, Tamura M, Taylor ML, Miller GF, Poonwan N, Taylor JW. Phylogeography of the fungal pathogen Histoplasma capsulatum. Molecular Ecology, 12 (12): 3383-3401. 2003.

26. Kauffman CA. Histoplasmosis: a clinical and laboratory update. Clinical Microbiology Reviews, 20 (1): 115-132. 2007.

27. Lack P. Pigeons and Doves. $2^{a}$ Ed. Editorial Oxford University Press, Oxford, USA: 288-295. 2003.

28. Lara H, Ayala N, Rodríguez C. Laboratorios de bioseguridad nivel 3 y 4: Investigación de patógenos peligrosos. Revista Mexicana de Patología Clínica, 54 (4): 177-186. 2007.

29. López C. Dimorfismo y patogenia de Histoplasma capsulatum. Revista Argentina de Microbiología, 38: 235-242. 2006.

30. López R. Ecología de los hongos patógenos para el hombre. Revista Mexicana de Micología, 21 (1): 87-91. 2005.

31. Maresca B, Kobayashi GS. Dimorphism in Histoplasma capsulatum: a model for the study of cell differentiation in pathogenic fungi. Microbiology Rev, 53 (2): 186209. 1989.

32. Miller J. Zoonosis de los pequeños animales. Tratado de Medicina Interna Veterinaria, 4ª edición, Vol. I. Ed Intermédica, Buenos Aires, Argentina: p 342-420. 1997.

33. Muñoz C, Cano L, González A. Detección e identificación de Histoplasma capsulatum por el laboratorio: de los métodos convencionales a las pruebas moleculares. Infectio, 14 (2): 145-158. 2010.

34. Parra Y, Torres A. Prevalencia y factores de riesgo para Histoplasma capsultum en el personal que labora en la Universidad de los Llanos Sede Barcelona, Villavicencio, I periodo. (III Fase de búsqueda de casos). Tesis de Pregrado Enfermeria, Universidad de los Llanos: p 3-44. 2010. 
35. Restrepo A. Histoplasmosis. En: Ed. Restrepo A, Robledo J, Leiderman E, Restrepo M, Botero D, Bedoya V. Enfermedades Infecciosas, 6 $\mathbf{a}$ Ed, Fondo Editorial CIB, Medellín, Colombia: p 316-326. 2003.

36. Sahaza J, Pérez A, Zenteno E, Taylor M. Usefulness of the murine model to study the immune response against Histoplasma capsulatum infection. Comparative Inmunology, Microbiology and Infectious Diseases, 37 (3): 143-152. 2014.

37. Sánchez M. Histoplasmosis, la micosis del viajero. Enfermedades Infecciosas y Microbiología, 29 (3): 111-116. 2009.

38. Taylor ML, Chávez CB, Rojas A, Reyes R, del Valle MB, Zúñiga G. Geographical distribution of genetic polymorphism of the pathogen Histoplasma capsulatum isolated from infected bats, captured in a central zone of Mexico. FEMS Immunology \& Medical Microbiology, 45 (3): 451-458. 2005.

39. Teniente M. Diseño de un plan de interpretación para la conservación de la cueva "Las Grutas" de ciudad Hidalgo, Michoacán. Tesis de Pregrado Bióloga, Universidad Nacional Autónoma de México. México D.F. 99 p. 2008.

40. Tkach A, Moreno J, Bava A. Diagnóstico presuntivo de histoplasmosis en un frotis sanguíneo. Acta Bioquímica Clínica Latinoamericana, 46 (4): 677-681. 2012.

41. Tobón, A. Epidemiologia de la histoplasmosis en pacientes infectados por el virus de la inmunodeficiencia humana. En: XV Congreso Colombiano de Parasitología y Medicina Tropical. Biomédica, 31 (3): 221-223. 2011.

42. Tobón, A. Protocolo de estudio y manejo de histoplasmosis. Infectio, 16 (3): 126128. 2012.

43. Toranzo Al, Tiraboschi IN, Fernández N, Ibarra B, Rivas M, Lee W, Davel G, Canteros CE. Diagnóstico molecular de histoplasmosis humana en muestras de sangre entera. Revista Argentina de Microbiología, 41 (1): 20-26. 2009.

44. Torres J, Ribas E, Gascón J, López O, Espasa M. Utilidad diagnóstica de la prueba intradérmica con histoplasmina, en áreas no endémicas de histoplasmosis. Revista Iberoamericana de Micología, 17 (3): 97-101. 2000.

45. Ueda Y, Sano A, Tamura M, Inomata T, Kamei K, Yokoyama K, Kishi F, Ito J, Mikami Y, Miyaji M, Nishimura K. Diagnosis of histoplasmosis by detection of the internal transcribed spacer region of fungal rRNA gene from a paraffin-embedded skin sample from a dog in Japan. Veterinary Microbiology, 94 (3): 219-224. 2003.

46. Ulloa M, Lappe P, Aguilar S, Park H, Pérez A, Toriello C, Taylor ML. Contribution to the study of the mycobiota present in the natural habitats of Histoplasma capsulatum: an integrative study in Guerrero, México. Revista Mexicana de Biodiversidad, 77 (2): 153-168. 2006.

47. Wheat LJ, Freifeld AG, Kleiman MB, Baddley JW, McKinsey DS, Loyd JE, Kauffman CA. Clinical practice guidelines for the management of patients with histoplasmosis: 2007 Update by the Infectious Diseases Society of America. Clinical Infectious Diseases, 45 (7): 807-825. 2007.

48. Zerpa R, Béjar V, Rojas R. Agentes de infecciones por hongos dimórficos y Cryptococcus neoformans. Revista Peruana de Medicina Experimental y Salud Pública. 28 (4): 685-687. 2011. 